\title{
Article
}

\section{Energy-Saving Structures of Road Embankments and Hydraulic Structures in The Arctic}

\author{
Anatoly Shuvaev ${ }^{1}$, Igor Sakharov ${ }^{2}$, Sergey Kuyukov ${ }^{3}$, Marina Panova ${ }^{3}$, Vladislav Pushkarev ${ }^{1}$, Kirill Plesovskikh ${ }^{1}$ \\ 1 Arctic Research Center of the Yamal-Nenets Autonomous District, Salekhard, Russia; ncia@yanao.ru \\ 2 Saint Petersburg State University of Architecture and Civil Engineering, Saint Petersburg, Russia; in- \\ tern.depart@spbgasu.ru \\ 3 Industrial University of Tyumen, Tyumen, Russia; general@tyuiu.ru
}

\begin{abstract}
Currently, the design and construction of embankments of roads, railroads and hydraulic structures are based on regulatory documents developed 25-30 years ago. For the construction of granite massifs it is necessary to use sandy soils, the distribution of which in the Arctic zone of Siberia in the areas of construction is not more than $1.5 \%$. In this case, the range of transport of sand in the alluvial area is 35 kilometers, in the rest of the area - an average of 60 kilometers. Large volumes of soil massifs require large amounts of transportation units, fuel consumption and are accompanied by large emissions of hydrocarbons into the atmosphere. Over the past 15 years, the authors have developed designs and technologies that significantly reduce the energy consumption during the construction of soil embankments. Combined structures are cages made of geosynthetic materials filled with unsuitable melted and frozen overmoistened clay and peaty soils. This allowed the use of soils within the construction sites and thereby reduce the range of transportation from 0.2 to 2.0 kilometers. As an example, when reducing the range of transportation from $25 \mathrm{~km}$ to $1 \mathrm{~km}$, the energy consumption is reduced by a factor of 21 . The use of geosynthetics made it possible to set the initial parameters of the water-heat regime control process, which increased the life cycle of the embankment from 2 to 5 times in comparison with traditional soil massifs and reduced the consumption of energy for repair and maintenance of linear transport structures. This article gives a theoretical substantiation of water-heat regime management, based on which new designs and technologies have been proposed and tested in Siberia in 2008-2013. The results of the tests confirm the theoretical research. Thus, the use of combined constructions of geosynthetics and inapplicable soils not only reduces the distance of transportation, but also reduces the volume of earthworks. It reduces the consumption of energy by 1.5-2 times.
\end{abstract}

Keywords: road; energy-saving constructions; temperature regime; deformation of the roadbed; water migration; compaction coefficient

\section{Introduction}

Erection of the road bed and railroads, until the mid-20th century, was carried out in summer only. At the same time, the technological interruption between the completion of the embankment fill and the construction of the roadway as well as the track superstructure increased the construction period. This was due to the lack of ways and management methods for the formation of strong and stable soil masses. The process was due to the natural consolidation of the soil over time. Currently, $95 \%$ of the earth works are carried out in winter. In the process cycle, one of the main requirements is to use only thawed soil. After the work is completed, the ground freezes within a few days. In this case, the transition of water into the solid phase shows irreversible deformation, decompaction of the soil of the earth bed. This is especially characteristic of the northern territories of Russia with its very low and prolonged air temperatures. Thus, according to the results of surveys of the field road network of the Priobskoye group of deposits since 
1980 till 1995, carried out by ROSDORNII (Moscow) and SOYUZDORNII (Moscow), since 2005 till 2013, and TGASU (Tyumen) for 15 years, the embankment soils coefficient of compaction decreased from 0.98 to 0.86 . The second feature is the lack of studies of moisture migration from the lower layers of the embankment to the upper layers - up to the frost boundary. This is especially relevant for soil embankments more than two meters high, dumped from cohesive and sandy dusty soils. The duration of soil stabilization is affected by soil types, hydrogeological conditions and other features. The average compaction factor was 0.89 , which is less than the required value (0.95), and the moisture content of the soils in the upper part of the embankment is generally greater than the optimum of 10 to $40 \%$.

The purpose of this research is to model the water-thermal regime of soil embankments. To solve the purpose of this research, it is necessary to solve the following tasks:

1. Development of a mathematical model to calculate the change in time and space of the main parameters of embankment soils: moisture $\mathrm{W}(\mathrm{x}, \mathrm{y}, \mathrm{z}, \mathrm{t})$; ice content $\mathrm{L}(\mathrm{x}, \mathrm{y}, \mathrm{z}$, $\mathrm{t})$; temperature $\mathrm{T}(\mathrm{x}, \mathrm{y}, \mathrm{z}, \mathrm{t})$.

2. To carry out full-scale and laboratory model studies of the water-heat regime of embankment soils during a single freezing-thawing cycle.

\section{Theoretical background}

In the current regulatory documents $[4,5]$ the basic principles and rules of construction of the roadbed in winter conditions developed in the 50-60s remain unchanged, despite the results of scientific research of road scientists and extensive domestic and foreign experience. In the documents governing the construction of soil embankments there are no methods of formation of combined structures based on soils and geosynthetics, not enough attention is paid to the physical processes occurring in the multiphase system.

The stages of earth bed formation during one freezing-thawing cycle include the following: compaction of soil during backfilling, freezing of soil after backfilling for several weeks, thawing of the soil mass.

After compaction to the required density values is completed, the water increases in volume by up to $9 \%$ in the process of further freezing. With soil moisture of 10 to $20 \%$, which is typical for coarse and medium-grained sands, the maximum heaving (due to water crystallization only) can be $0.9-2.5 \%$.

Heaving of silty clay soils can be several times greater than these values. This is explained by the migration of moisture from the lower horizons into the freezing zone (Figure 1) [7]. Studies showed that in the process of moisture migration in freezing soils, the adsorption forces of the mineral skeleton, which determine the "crystallization-film mechanism" of moisture movement to the freezing front, are of primary importance.

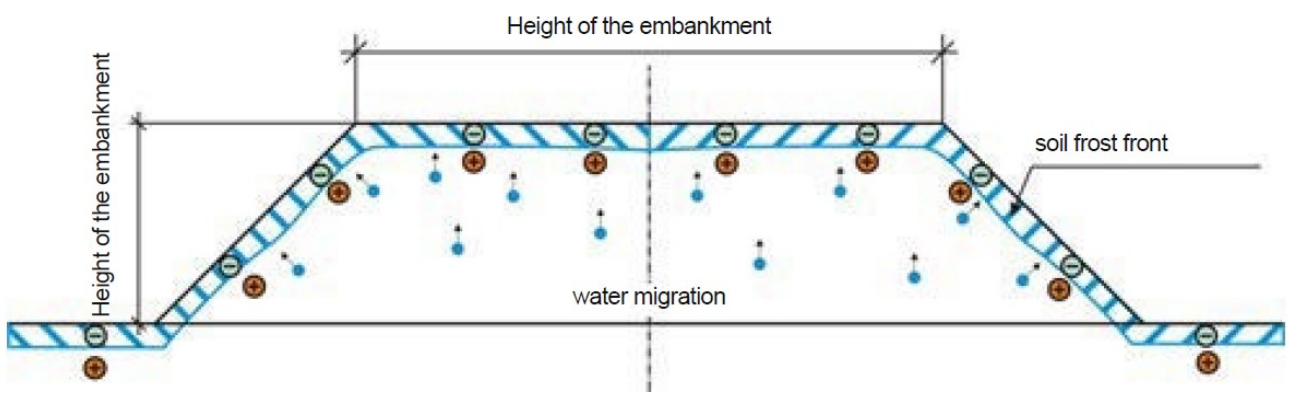

Figure 1. Water migration during the embankment soil freezing.

The proposed fundamentally new physical and mathematical model, unlike the known ones, takes into account the mutual influence of the temperature field, moisture distribution and ice content. 
The adopted quasi-three-dimensional approach to the mathematical modeling of the water-heat regime allows us to operate with two variables $y$ and $\mathrm{z}$ and time $\mathrm{t}$ in the calculated equations, which makes it possible to predict changes in temperature and humidity over time.

The physical basics of modeling are: the law of energy conservation (thermal balance) in the form of the thermal conductivity equation, taking into account the heat of phase transitions, the equations of moisture balance in different phases, which determine

moisture saturation in different parts of the considered area. The fluxes $\overline{\boldsymbol{h}_{\boldsymbol{}}}$ and velocities

of matter $\bar{v}$ in the solid phase: for soil skeleton $\overline{\eta_{1}}=$ and ice $p_{1} \overline{v_{I}} \bar{s}=p_{3} \overline{v_{3}}$ are related exclusively to the deformation motion and are defined by the equations [3].

At the boundary of layers of different wet ground materials, moisture spikes $W$ are possible. For different types of soils, the equality of moisture transfer potentials $\theta$ takes place. In such an expression, recording the intensities of water and steam-air mixture

flow $\overline{\boldsymbol{V}}_{2}$ in the form of relation (1) makes it possible to calculate the fields of moisture, ice content and steam content within the framework of uniform calculation formulas, but with the use of variable coefficients of heat and moisture transfer.

$$
\overline{V_{2}}=p_{2} \overline{v_{2}}=-\lambda_{2 m} \nabla \theta-\lambda_{2 n}^{T} \nabla T-k_{2} \nabla P
$$

where: $\nabla \theta=\frac{1}{c_{m}}(\nabla w)_{T}-$ moisture transfer gradient; $C_{m}=\left(\frac{d w}{L \theta}\right)_{T}-$ isothermal specific moisture capacity; $\lambda_{2 m}=a_{2 m} p_{1} C_{m}$ - moisture conductivity coefficient; $\lambda_{2 m}^{T}=\frac{\lambda_{m m}}{\varepsilon_{m m}} \delta$ - coefficient of thermal conductivity; $\mathrm{a}_{2 \mathrm{~m}}=\mathrm{a}_{2 \mathrm{~K}}+\mathrm{K}_{n \sim} ; \mathrm{a}_{2 \kappa}$ - water diffusion coefficient in the ground, Кпл - coefficient of isothermal film motion of liquid in the ground.

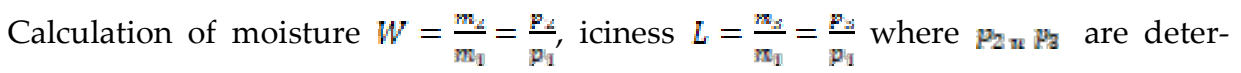
mined from equation (1) by solving the full system of equations. Moisture transfer coefficients are determined from experimental data, taking into account the variability of moisture. With moisture $0<\mathrm{W}<\mathrm{W}_{\mathrm{Mr}}$, where $\mathrm{W}_{\mathrm{Mr}}$ - the maximum hygroscopic moisture capacity, moisture migration occurs mainly in the form of diffusion of unsaturated vapor.

The heat transfer equation in the embankment in its integral form is written as relations (2-6):

$$
\begin{aligned}
& \int_{v} \frac{d p_{1}}{d t} d V=-\int_{s} p_{1}\left(\bar{v}_{1}\right)^{n} d s \\
& \int_{V} \frac{d y_{2}}{d t} d V=-\int_{\Sigma}\left[\nabla \lambda_{\operatorname{Im}_{m}}(\nabla \theta)^{n}+\lambda_{2 \pi}^{m}(\nabla T)^{n}+k_{2}(\nabla P)^{n}\right] d S+\int_{V} J_{8 z} \lambda V+\int_{V} J_{4 \Sigma} d V \\
& \int_{V} \frac{d y_{3}}{d t} d V=-\int_{S} J p_{a}\left(\bar{v}_{a}\right)^{n} d s-\int_{V} J_{32} d V \\
& \int_{v} \frac{d p_{4}}{d t} d V=-\int_{s}\left[\lambda_{4 m}(\nabla \theta)^{n}+\lambda_{4 m}^{T}(\nabla T)^{n}+k_{4}(\nabla P)^{n}\right] d S-\int_{V} J_{42 d V} \\
& \int_{V}\left(\sum_{i=1}^{4} c_{i} p_{i}\right) \frac{d T}{d t} d V=-\int_{\Omega} \lambda(\nabla T)^{\mathrm{n}} d S-\int_{V}\left(I_{32} J_{32}+I_{42} J_{42}\right) d V
\end{aligned}
$$
(7):

The heat balance equation can be represented in the form of the following equation

$$
\int_{V} \frac{d(v H)}{d t} d V=-\int_{G} \lambda(\nabla T)^{\mathrm{n}} d S
$$


where $\mathrm{H}=\int_{0}^{\mathrm{T}} \mathrm{C}_{\mathrm{s \Phi}} \mathrm{dT}$ is the equivalent enthalpy of the ground mixture.

In this approach, due to the calculated heat flux, $q=-\int_{\Omega} \lambda(\nabla T)^{\mathrm{n}} d S$ the enthalpy increment $\nabla H^{*}=q \frac{\nabla \mathrm{v}}{p v^{\prime}}$, which includes the heat of phase transformations, is determined.

In an equilibrium process in the phase transition zone, the calculation of the unfrozen water content $\mathrm{W}_{\mathrm{H} 3}=\mathrm{W}_{\mathrm{H} 3}(\mathrm{t})$ is determined by inverse interpolation of the temperature $\mathrm{T}$ by the found enthalpy $\mathrm{H}$.

To analyze the thermal-moisture state of the ground, data are set at the initial time $t=0$ in the following form: $T=T_{o}(x, y, z, t) ; p_{i}=p_{j}(x, y, z, t)$; where $v j=1,2,3,4$ in the considered calculation area. Based on the experimental data, the following can be given: wet soil density Q, moisture content $\mathrm{W}$, ice content $\mathrm{L}$, as well as porosity e and true density $\mathrm{p}{ }^{(0)}$ of the soil skeleton. In this case, the densities $\mathrm{p}_{1}$ are pre-calculated through the $\mathrm{p}, \mathrm{W}$, $\mathrm{L}, \mathrm{p}_{1}, \mathrm{~T}$ measured under natural conditions or taken under similar conditions.

The boundary conditions for heat and moisture transfer are set at the outer surface $[1,2]$ and at a distance in depth from the surface. To calculate the temperature, the unsteady conditions on the outer surface are defined by equation (8):

$$
\left(\alpha \frac{d T}{d n}\right)_{F}+\alpha\left(T_{F}-T_{6}\right)+p_{2} \alpha_{a F} \frac{p_{F}}{b_{F}}\left(W_{F}-W_{\mathrm{B}}\right)=0
$$

To calculate the moisture content $W=\frac{p_{2}}{p_{1}}$, the unsteady conditions on the outer surface can be determined from equality (9):

$$
\lambda_{\mathrm{a} F} \frac{P_{F}}{b_{F}}\left(\frac{d W}{d n}\right)_{F}+\lambda_{a F} b_{F}\left(\frac{d T}{d n}\right)_{n}+\lambda_{a} \frac{P_{F}}{b_{F}}\left(W_{F}-W_{B}\right)=0
$$

In ratios (8), (9): $\alpha, \alpha_{3 \mathrm{~F}}$ - heat and moisture transfer coefficient of the road surface and road side slopes, Тв and $W_{в}$ ваre - temperature and humidity of surface air.

\section{Laboratory tests}

To study the formation of embankment soils in the first year after construction, laboratory research were carried out on model embankments, according to the methodology developed by the authors.

The following parameters were determined during the tests: deformation (heaving) at three points on the surface of the model embankment, soil moisture before freezing and after complete thawing, soil density before freezing and after complete thawing, temperature at various points of the model embankment.

To conduct research, an installation consisting of a rectangular box (tray) was assembled, in which a soil model of the embankment is located. Inner sizes of the tray: $180 \times 61 \times 35 \mathrm{~cm}[6]$.

To create the necessary temperature regimes a freezer of KXH 2-6 brand was used. The inner volume of the chamber is $8 \mathrm{~m} 3$. The temperature of the embankment soil was monitored by DS 18 S20 temperature sensors and Thermoscan temperature measurement complex (Figure 2).

To study the deformation occurring on the surface of the embankment, we made a device consisting of clock-type indicators fixed on a frame and video cameras, allowing to record the readings of indicators automatically, in remote mode (Figure 2). 

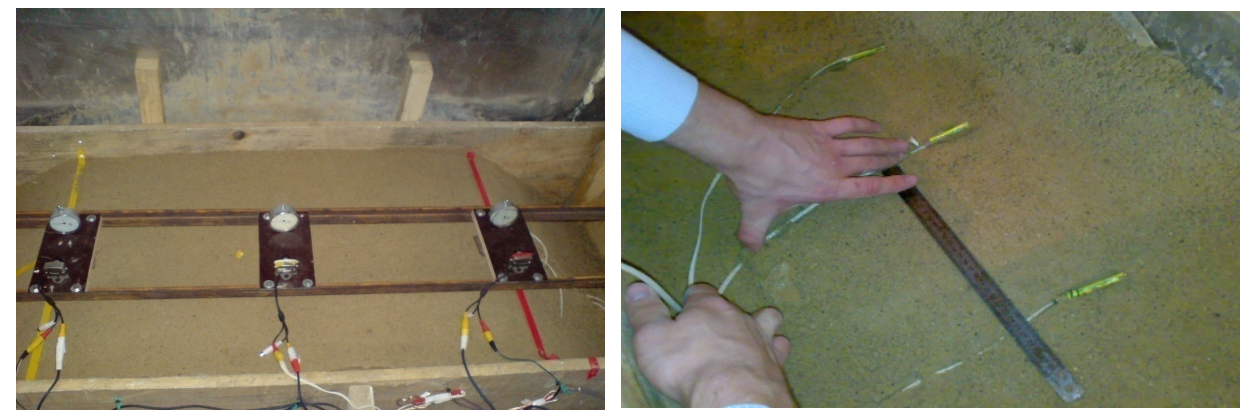

Figure 2. Model tests of an earth embankment

Two series of tests with different types of soils were conducted to determine the patterns of change in embankment properties during freezing and thawing. Medium-sized sand and loam were used as the soils under study. The model embankment was formed in layers with compaction of each layer by vibroplate SO-309 and hand tamping to the compaction coefficient of 0.93-0.97. In addition, in each layer, the moisture content of the soil was determined at several points.

Freezing of the model embankment was carried out until the temperature in the body was completely stabilized, after which thawing was carried out. The temperature measurement was carried out automatically after 1 minute, and the change in deformations was recorded in real time.

After the end of the experiment, control samples were taken to determine the density and humidity of the thawed soil.

The temperature regime of the model embankment made of sandy and clay soil, at its freezing \& thawing, is determined during the testing process (Figure 3,4).

The freezing-thawing process has the same character for all three sensors (points). However, there are fundamental differences in the transition of $0^{\circ} \mathrm{C}$. Thawing takes more time than freezing.

The rate of the temperature dropping to $0^{\circ} \mathrm{C}$ and the rate of freezing for sandy soils is about the same, for clay soil the rates are different. When thawing both sandy and clay soil, the thawing rate from $0^{\circ} \mathrm{C}$ to ambient temperature is less than the thawing rate from -13 to $0^{\circ} \mathrm{C}$. This indicates that due to the transition from solid to liquid phase, the migration of moisture affects the rate of thawing.

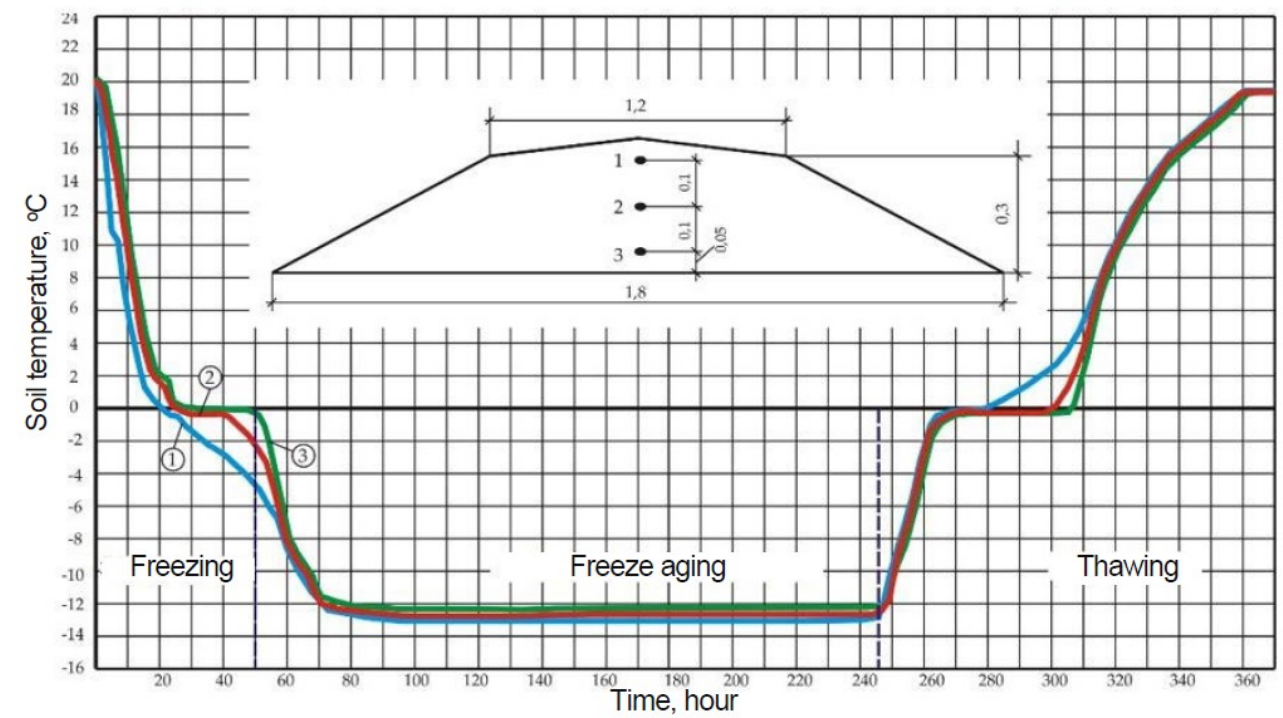

Figure 3. The freezing-thawing schedule for a model embankment of loam $1,2,3$ - locations of temperature sensors 


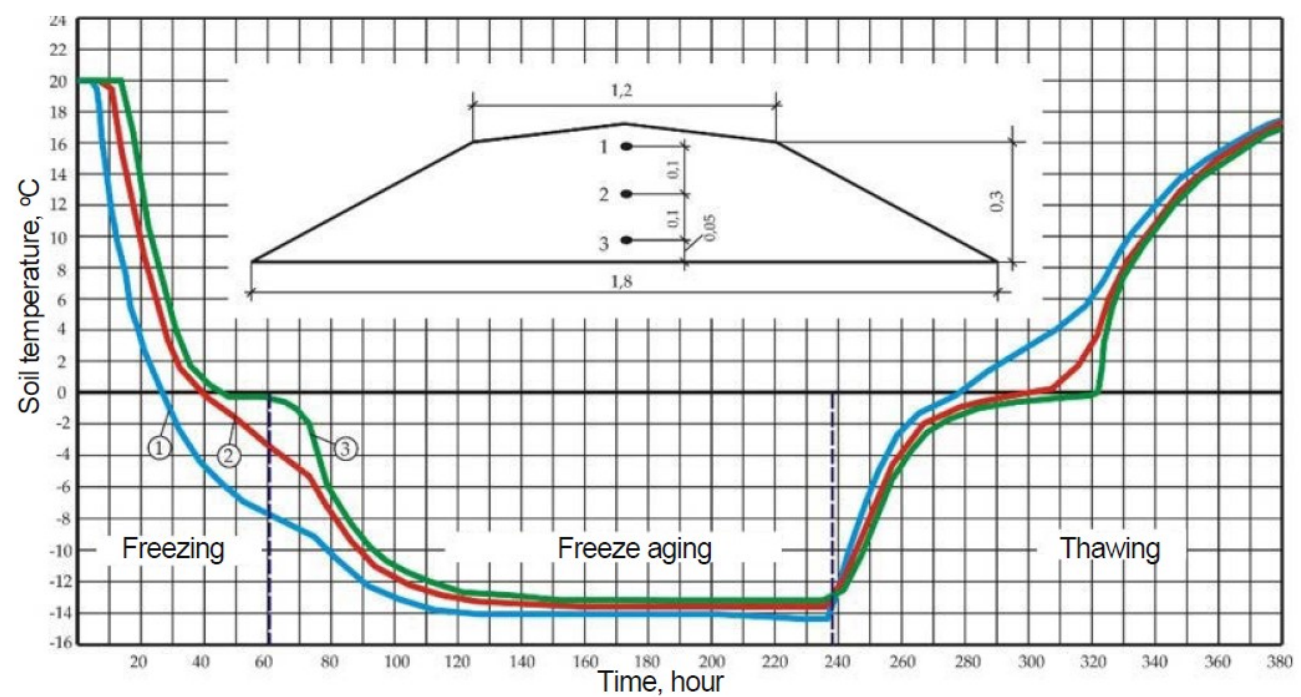

Figure 4. The freezing-thawing schedule for a model embankment of sand $1,2,3$ - locations of temperature sensors

The indicators installed on the surface of the model embankment made it possible to record the embankment deformation amount during freezing-thawing, as well as to determine the dynamics of changes in the compaction coefficient (Figure 5,6).

Assessing the deformation of the embankment by the compaction coefficient, we can state that with the initial compaction coefficient of 0.97 after the freezeing-thawing processes, the compaction coefficient decreased to 0.965. Moreover, the compaction coefficient changes during freezing and thawing, the minimum value of 0.92 corresponds to the period of the embankment complete freezing. For clay soil, respectively, with 0.97, during thawing after heaving - 0.88, and after the end of complete thawing - 0.925 .

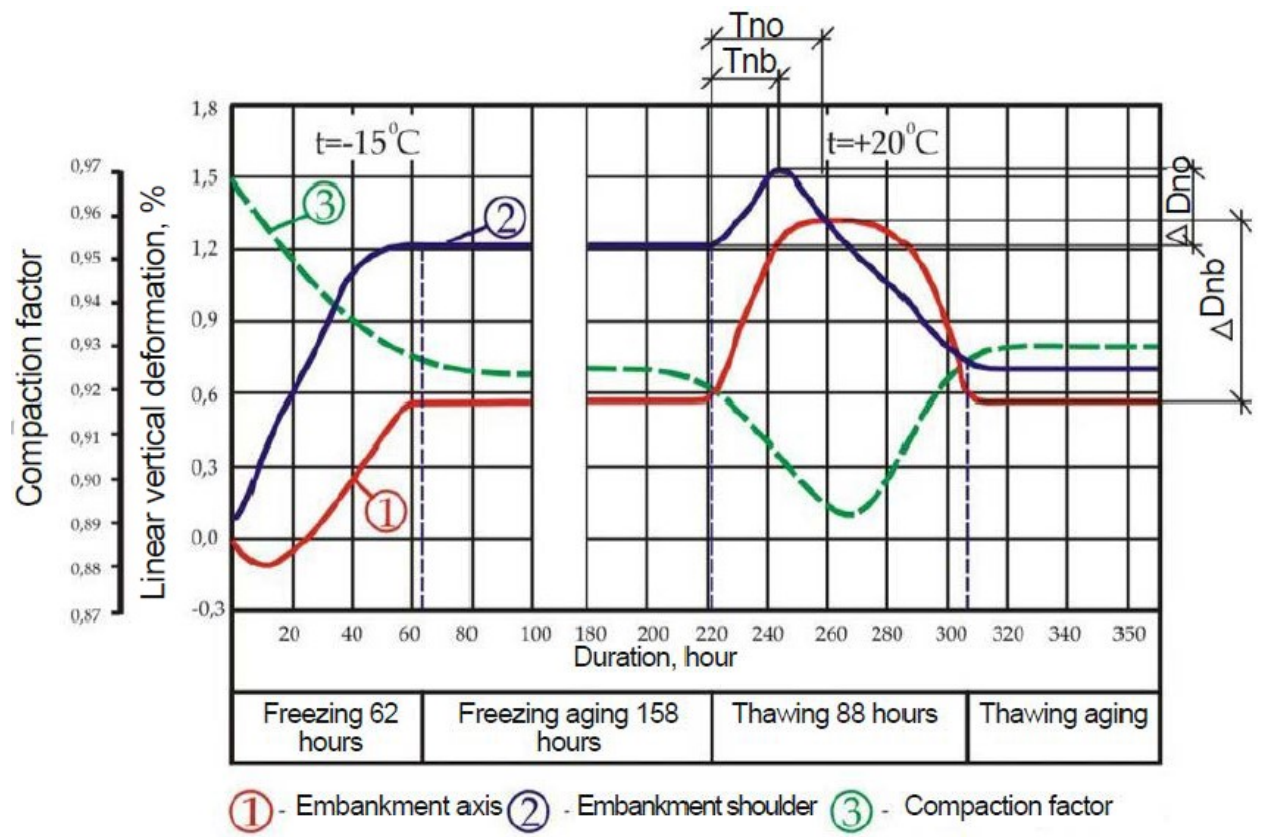

Figure 5. Deformations of the embankment of clay soil during freezing-thawing

1 - Linear vertical deformation along the embankment axis, 2 - Linear vertical deformation along the embankment shoulder, 3 - Compaction factor, $\Delta$ Dno - swelling deformation along the embankment axis, $\Delta$ Dnb - swelling deformation along the embankment shoulder, Tno (Тно) - duration of swelling along the embankment axis, Tnb (Тнб) - duration of swelling along the em- 
When freezing clay soil, the deformation is 2.5-3 times greater than that of sand. The thawing process occurs differently, in the initial stage there is a sharp swelling along with this increase in deformations up to $20 \%$ after which there is a damping of deformations. Moreover, in the middle part of the embankment, the swelling processes are less in magnitude, but longer in time. The nature of the change is smooth.

Assessing the deformation of the embankment by the compaction coefficient, we can state that with the initial compaction coefficient of 0.97 after the freezeing-thawing processes, the compaction coefficient decreased to 0.925. Moreover, the compaction coefficient changes during freezing and thawing, the minimum value of 0.88 corresponds to the period of swelling during thawing. After the end of complete thawing, the compaction coefficient was 0.925 .

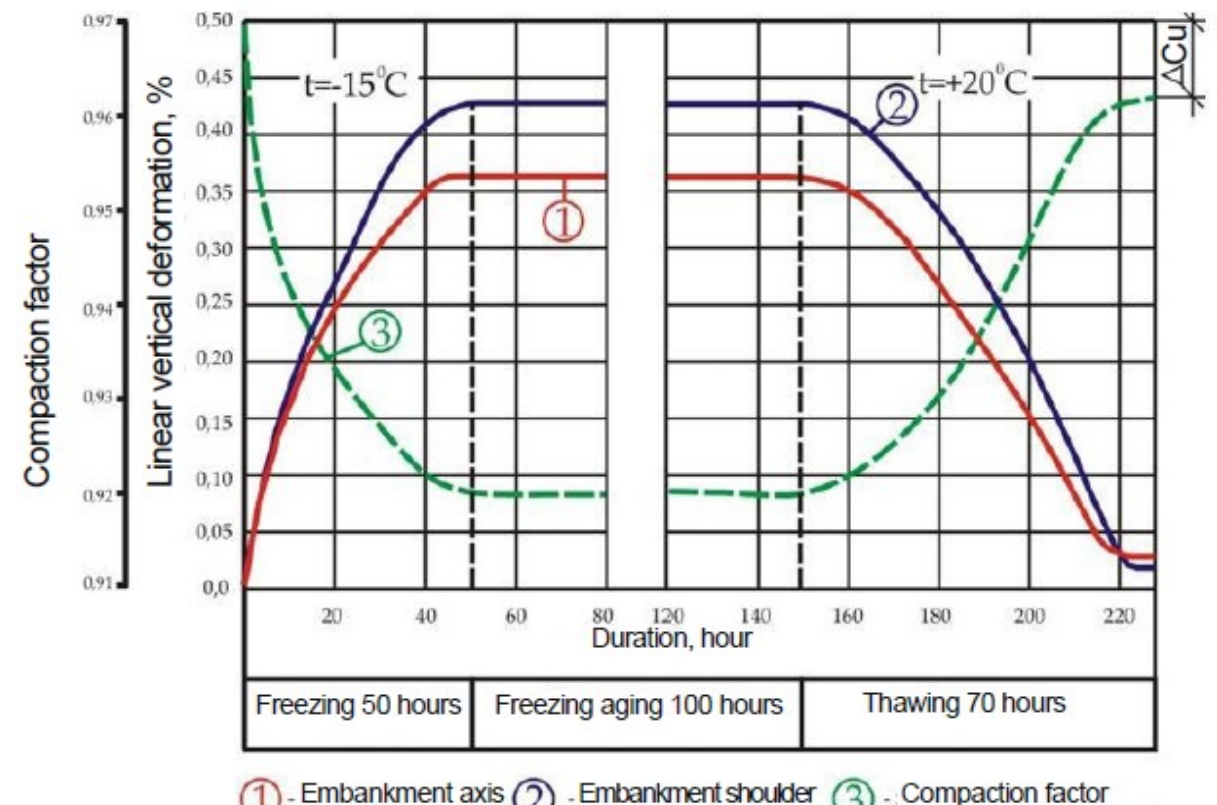

Figure 6. Deformations of the sand soil embankment during freezing-thawing

1 - Linear vertical deformation along the embankment axis, 2 - Linear vertical deformation along the embankment shoulder, 3 - Compaction coefficient, $\triangle \mathrm{Cu}$ - change in compaction coefficient relative to the initial state

\section{Field observations}

To predict the water-heat regime of soil embankments using the proposed basis for the mathematical modeling outlined above, experimental work was carried out in 2017-2019 on field roads of the Urengoy group of deposits. In the process of work, the geometric parameters, temperature and moisture content of soils were determined both in the body of the embankment and at the base. The results of measurements show a significant deformation of the soil embankment due to its base sediment $\mathrm{S}=0.5-1.5 \mathrm{~m}$. The reason for this process is the thawing of the base soil, i.e. the position of the permafrost boundary does not correspond to the first principle of soil embankments design in the first road-building climatic zone.

Calculations show that the bulk of the free water should move to the subcuvette areas of the embankment (Figure 7), where the moisture content should correspond to the moisture content of the frozen soils of the embankment base. It is confirmed by the results of field tests. 


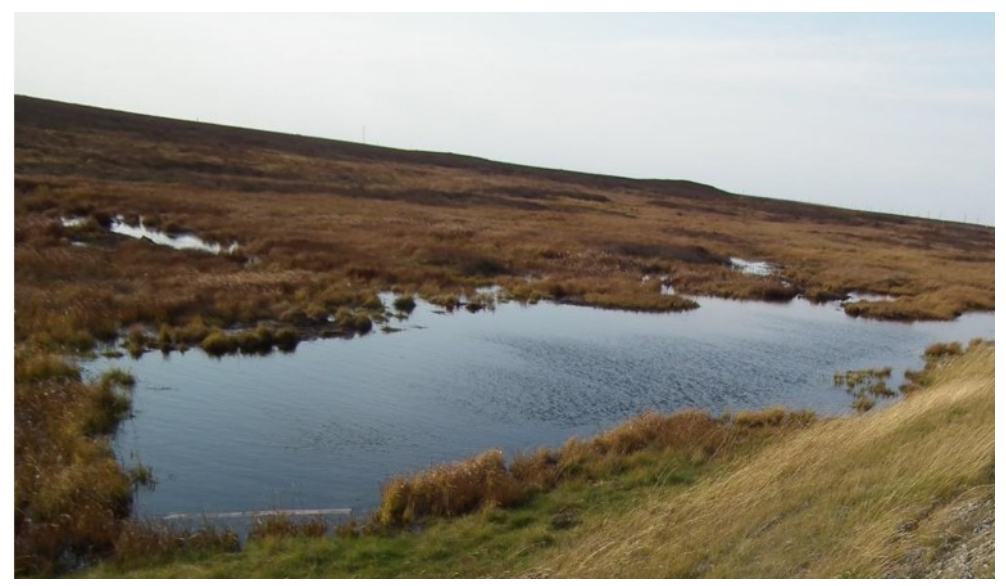

Figure 7. Water accumulation in the cuvette areas

In this case, the water formed in the process of thawing, as a coolant, fundamentally contributes to changing the boundary of permafrost soils. The amount of thawing (active layer) approximately corresponds to the embankment height $=1.5-2.5 \mathrm{~m}$ (Figure 8).

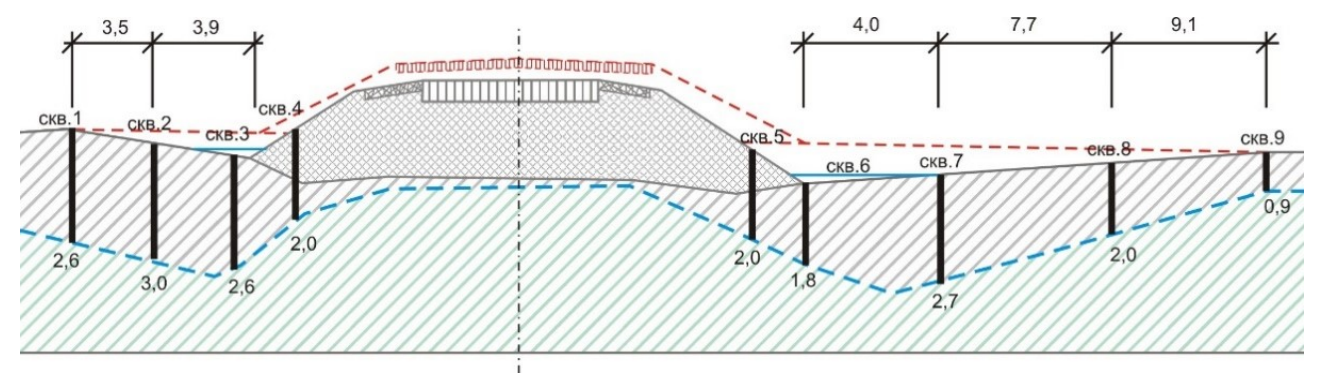

Figure 8 . The actual position of the permafrost soils boundary (autumn)

dimensions are in meters

Moisture of the soil in the embankment lower zone in autumn-winter corresponds to the natural moisture content of its base soils ( $\mathrm{W}=40-60 \%$ ), and in winter-spring (at the end of the freezing period) moisture content of the embankment soils increases to full moisture capacity and above the moisture content of natural base soils by $10-15 \%$ and is $50-70 \%$ (Figure 9).

There is a process of water accumulation at both bottoms of the embankment and in the upper part of the roadbed under the pavement, which is a major factor in the loss of embankment stability and destruction of the pavement.

a)

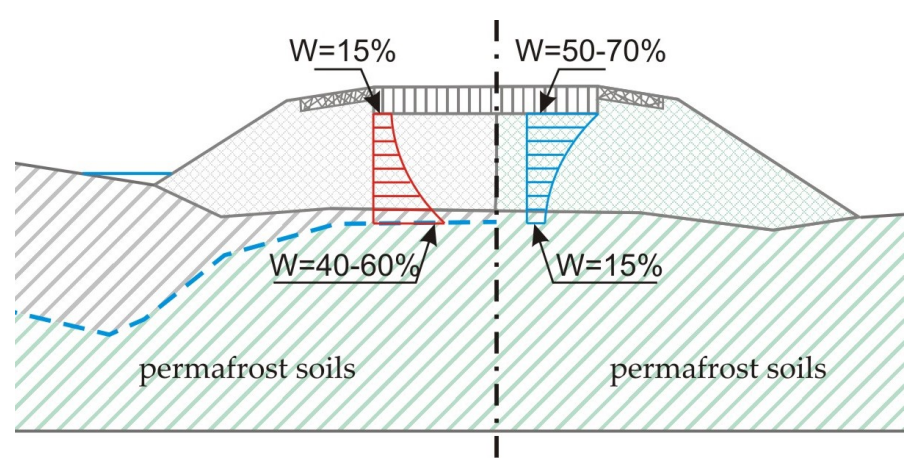

Figure 9. Diagrams of soil moisture during the year in the embankment during the year $\mathrm{a}$ - summer, $\mathrm{b}$ - winter 


\section{Proposed energy-saving constructions}

The obtained theoretical foundations, as well as the laboratory and field studies, necessitate the development of fundamentally new structures of the subgrade. The subgrade structures that were developed by the authors for the Arctic zone (Figure 10) allow using inapplicable soils in combination with geosynthetic materials. The proposed structure due to the use of thermal insulation material can significantly reduce the volume of imported soil, and by using inapplicable soil, located at a distance of no more than 2 kilometers from the object under construction, to reduce energy consumption.

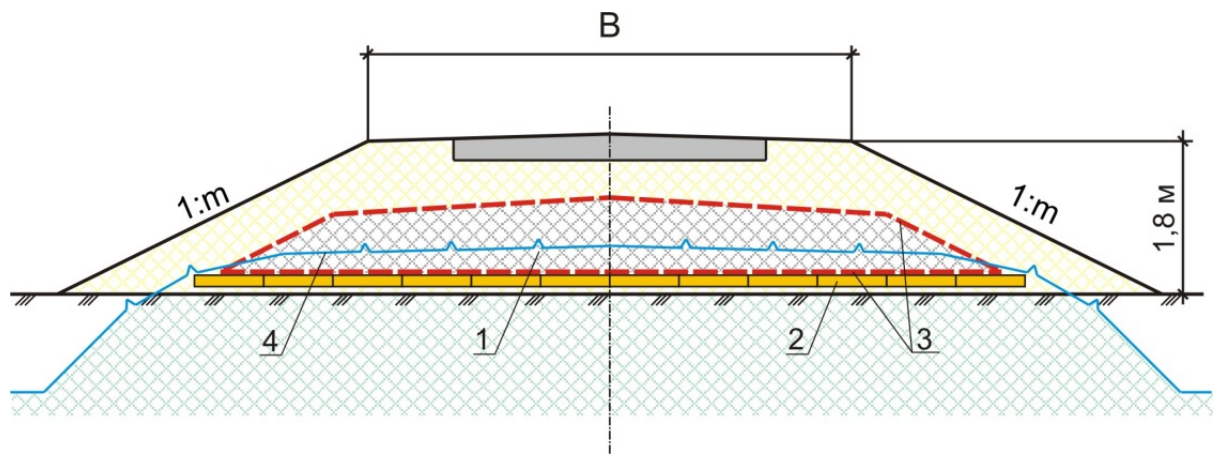

Figure 10. Proposed structures of the earth subgrade on permafrost soils

1 - geosynthetic casing of inapplicable soil, 2 - thermal insulator, 3 - geosynthetic material, 4 boundary of permafrost soils.

One of the criteria for evaluating the effectiveness of new structures in addition to the pace of work and the cost of production is the energy intensity of the construction process. A comparative analysis of the energy input level of construction and installation works in the proposed structure erection and the traditional one shows the effectiveness of the proposed solution (Table 1).

Table 1. Comparison of structures

\begin{tabular}{lccc}
\hline \multicolumn{1}{c}{ Parameter } & $\begin{array}{c}\text { Measure } \\
\text { Unit }\end{array}$ & $\begin{array}{c}\text { Traditional } \\
\text { structures }\end{array}$ & $\begin{array}{c}\text { Proposed struc- } \\
\text { ture }\end{array}$ \\
\hline Volume of soil per 1 km & $\mathrm{m}^{3}$ & 46000 & 28000 \\
\hline Amount of work per shift & $\mathrm{m}^{3}$ & 4600 & 2800 \\
\hline Range of soil transportation & $\mathrm{km}$ & 25 & 1 \\
\hline Average speed of trucks & $\mathrm{km} / \mathrm{h}$ & 40 & 10 \\
\hline Carrying capacity of trucks & $\mathrm{tn}$ & 25 & 25 \\
\hline Required number of trucks & $\mathrm{pcs}$. & 44 & 10 \\
\hline Number of truck trips & $\mathrm{pcs}$ & 7 & 28 \\
\hline Mileage per one truck & $\mathrm{km}$ & 350 & 56 \\
\hline Total mileage of trucks & $\mathrm{km}$ & 15400 & 60 \\
\hline Petrol consumption & $1 / 100 \mathrm{~km}$ & 50 & 336 \\
\hline Total petrol consumption & 1 & 7700 & 3546 \\
\hline Total capacity of construction equipment & $\mathrm{kW}$ & 14290 & 1.27 \\
\hline Energy consumption intensity & $\mathrm{kW} / \mathrm{m}^{3}$ & 3.10 & \\
\hline
\end{tabular}

\section{Results}

Thus, the analysis of the data obtained in the course of laboratory research and experimental work allows us to formulate the following conclusions: 
- a mathematical model of moisture migration and temperature change was obtained, which makes it possible to take into account the types of soils used and determine their effective and optimal placement to ensure embankment stability.

- theoretical foundations are confirmed by field and model studies, allow the use of inapplicable soils together with geosynthetic materials

- the developed combined structures allow significantly reducing the energy consumption for the Arctic zone from an average of $3.10 \mathrm{~kW} / \mathrm{m} 3$ to $1.27 \mathrm{~kW} / \mathrm{m} 3$.

Author Contributions: Conceptualization, A.S., S.K.; methodology, A.S., I.S., S.K., M.P.; data curation, S.K., M.P., S.B.; writing-original draft preparation, V.P., K.P.; writing-review and editing, A.S., I.S., S.K., M.P.; laboratory research, S.K., V.P., K.P.; field work, S.K., V.P., K.P. All authors have read and agreed to the published version of the manuscript.

Funding: This research received no external funding.

Conflicts of Interest: The authors declare no conflict of interest.

\section{References}

1. Zolotar' I.A. Calculation of freezing and the amount of heaving of the soil, taking into account the migration of moisture. - In the collection: Processes of heat and mass transfer in frozen rocks. - M.: Science, 1965. p. 19-25.

2. Zolotar' I.A. et al. Highways of the North. - M.: Transport, 1981.- p. 247.

3. Tsytovich N.A. Mechanics of frozen soils. M.: Higher school, 1973, p. 445.

4. Shuvaev, A.N. Physical and mathematical modeling of soil mounds, consisting of frozen soils/ A.N.Shuvaev// Bulletin of the Tomsk State University of Architecture and Civil Engineering. - 2016. - No. 5. - pp.167-173.

5. Abzhalimov R.Sh., Why the soil swells / R.Sh. Abzhalimov, N.N. Golovko // Highways. - 2008. - No. 11. - pp. $102-107$.

6. Zamyatin A.V. Stabilization of soil embankments erected in winter in the conditions of Western Siberia: dissertation of the Technical Sciences candidate: 05.23.02 / Zamyatin Alexey Valeryevich; Tyumen State Architectural Academy. - Tyumen, 2011. p. 145.

7. Kudryavtsev S.A. The influence of migrating moisture on the process of frost heaving of seasonally freezing soils / S.A. Kudryavtsev// Reconstruction of cities and geotechnical construction. - 2004. - No. 7. - pp.233-240. 